\title{
Prevalence and Social Contextual Factors of Smokeless Tobacco Use: Insights from Schools of Delhi, India
}

\author{
Akash Deep Sharma, Suneela Garg, Meghachandra M Singh, Chetana Prakash \\ Deshmukh*, Pragya Sharma, Amod L Borle
}

\begin{abstract}
Background: It was observed that adult users start tobacco use in childhood or adolescence. The influence of digital and print media, social acceptance among peers, and in order to mimic role models from films attracts youth towards tobacco. Hence this study was conducted to assess the prevalence of smokeless tobacco (SLT) use among school-going adolescents with the assessment of the influencing factors such as exposure at school, home, and public places along with the role of various media in SLT use by adolescents. Methods: Cross sectional study was conducted with 860 students of class $9^{\text {th }}-12^{\text {th }}$ enrolled in schools. Purposive sampling of three schools was done from the study area to reach desired sample size. All the students of class $9^{\text {th }}-12^{\text {th }}$ within selected schools were given chance to participate in the study. Data collection was done using pretested modified Global Youth Tobacco Survey (GYTS) questionnaire. Results: Consumption of smokeless tobacco (SLT) was observed in 79 (11\%) of 714 subjects. Significantly higher proportion (18.4\%) of study subjects consumed SLT who were exposed to tobacco at school premises and $19.1 \%$ of study subjects who were exposed to teacher using SLT in schools compared to non-exposed group. ( $\mathrm{p}=0.016)$. It was observed that $8.1 \%$ of subjects without any exposure to tobacco at home and $9.8 \%$ of subjects without exposure to tobacco at outdoor public space consumed SLT. Consumption of SLT use was highest (16.7\%) among subjects exposed to tobacco advertisement or promotion through social media $(\mathrm{p}=0.04)$. Conclusion: High prevalence of SLT was detected among adolescents in school. Factors such as exposure to tobacco at home, public places, school and school teacher using SLT, exposure of tobacco advertisement and promotion via different modes of media was found to be significantly associated with the use of SLT in the adolescents of school.
\end{abstract}

Keywords: Smokeless tobacco- adolescents- school

Asian Pac J Cancer Prev, 22 (8), 2351-2355

\section{Introduction}

The World Health Organization (WHO) has defined 'adolescents' as individuals in the age group of 10 to 19 years ("WHO | Adolescent health in the South-East Asia Region," n.d.).

Adolescents experience rapid physical, cognitive and psychosocial growth. This affects their emotional, social and psychological behaviour reflecting in their decision making and interaction with the world around them. It is a unique stage of human development and an important time for laying the foundations of good health ("WHO | Adolescent health,"n.d.).

It is estimated that $70 \%$ of premature deaths among adults are due to behavioral patterns that emerge in adolescence, including tobacco use, violence, and sexual behavior ("WHO |What about boys? A literature review on the health and development of adolescent boys,"2000).

It is observed that most of the adult users start tobacco use in childhood or adolescence (Chadda and Sengupta,
2002). It is also reported that youth initiating tobacco use in their adolescence will continue the consumption lifelong, with very low quitting rates (Thakur et al., 2014).

Adolescents are the most vulnerable population to initiate tobacco use as it is a developmental phase where behavior of an individual is influenced by emotional and social factors. The influence of digital and print media, social acceptance among peers and in order to mimic role models from films or social media attracts youth towards tobacco consumption. It is observed that tobacco and alcohol use are seen as symbols of maturity and independence among the young people (Soni and Raut, 2013).

Factors such as history of tobacco use by parents and elders at home, peer influence and pressure, the belief of association of tobacco use with masculinity and being "cool," urge to experiment, underlying emotional and psychological problems have been reported to be reasons for pushing youth towards tobacco consumption (Oswal, 2015). Advertisements of different tobacco products are 
extremely common in all types of media including the print media, Television and road-side hoardings add onto tobacco consumption practices by the youth. Tobacco publicizing adequately target the youngsters by showing consumers as stylish, sporty and successful (Chadda and Sengupta, 2002; Vaidya et al., 1996).

Apart from home and social environment, adolescents spend most of the time in educational institutions. Teachers are in close contact with students in this course and students mimic their teachers. Therefore, teachers can be one of the important influencing factors to promote the tobacco consumption among the adolescents. Consumption of tobacco is common among school teachers, despite having awareness about the harmful effects of tobacco (Mishra et al., 2019).

According to the 2000 Global School Personnel Survey (GSPS) India, 78\% of Bihar teachers used some form of tobacco. Later GSPS India (2006) showed nearly $40 \%$ of teachers in the eastern region of India, including Bihar used some form of tobacco, thus unknowingly promoting tobacco consumption (Nagler et al., 2015). Teachers represent key population for tobacco control efforts because they are role models for students, conveyor of tobacco prevention and influential members of society, capable of influencing both policies and social norms related to tobacco control (Nagler et al., 2015).

This study was conducted to assess prevalence of smokeless tobacco use among school going adolescents in senior secondary schools with the assessment of the influencing factors such as exposure at school, home and public places along with role of various media in smokeless tobacco use by adolescents.

\section{Materials and Methods}

This was a cross sectional study conducted over a period of one year in the catchment areas within 10 $\mathrm{km}$ from rural health training center of Department of Community Medicine, Maulana Azad Medical College New Delhi which is located in Barwala village in North West district of Delhi in India. The study population comprised of all the students of class 9th -12th enrolled in schools present in the study area. Sample size was calculated using the formula ( $\mathrm{n}=\mathrm{Z} \alpha 2 \mathrm{p} \mathrm{q} / \mathrm{L}$ 2)taking the prevalence to be $12.5 \%$ ("WHO | India (Ages 13-15) Global Youth Tobacco Survey (GYTS). Fact Sheet," n.d.) at $95 \%$ confidence level with relative error of $20 \%$ and considering $10 \%$ non-respondents sample size was estimated to be 740.After obtaining clearance from institutional ethics committee and permission from School Health Scheme, Delhi, total 3schools were selected in the study area for the study. The principals and class teachers of the school were approached and explained the nature and purpose of the study after which the permission to conduct study in the school was obtained. On the first visit to school the study subjects were addressed for a period of 10-15 minutes in which the procedure and context of the study was explained and any queries regarding their involvement in the study were addressed at that time. The study subjects were given participant information sheet and consent forms for their parents to participate in the study. All those whose parents consented for the study their children were given assent forms on the day of study. After that they were given with a self- administered questionnaire in Hindi. Data collection from the study subjects of one school were done at one time only. Of the 860 study subjects approached for the study 714 gave consent from parents and assent to participate in the study. The data collected was entered in MS Excel and analyzed using SPSS version 25. Data were expressed in percentage. $\chi^{2}$ test was used for comparison of qualitative data between groups. 'p' value less than 0.05 was considered as significant.

\section{Results}

\section{Characteristics of study subjects}

Table 1 show the characteristics of subjects who participated in the study. Consumption of smokeless tobacco (SLT) was observed in $79(11 \%)$ of 714 study subjects. There were total $609(85.3 \%)$ male participants out of which $62(10.2 \%)$ were consuming SLT whereas among 105 (14.7\%) female participants, 17 (16.2\%) females consumed SLT. Maximum proportion of SLT consumers were from $12^{\text {th }}$ class $(17.4 \%)$, living in joint families (12.0\%) and having higher socioeconomic status (13.7\%) The SLT consumption significantly increased with increase in class grade varying from $8.1 \%$ in $9^{\text {th }}$ class to $17.4 \%$ in class $12^{\text {th }}(p=0.017)$ (Table 1$)$.

A significantly higher proportion 51 (18.4\%) of study subjects consumed SLT who were exposed to tobacco (smoked and non- smoked) at school premises and 17

Table 1. Socio-Demographic Characteristicsof SLT Use among the Study Subjects $(\mathrm{N}=714)$

\begin{tabular}{|c|c|c|c|}
\hline Variables & $\begin{array}{l}\text { no }(\%) \\
\mathrm{N}=714\end{array}$ & $\begin{array}{c}\text { SLT use } \\
\text { no }(\%)(95 \% \text { C.I })\end{array}$ & $\chi 2, \mathrm{df}$, 'p' value \\
\hline \multicolumn{4}{|l|}{ Class } \\
\hline $9^{\text {th }}$ & $223(31.2)$ & $18(8.1)(4.8-12.5)$ & $10.207,3,0.017$ \\
\hline $10^{\text {th }}$ & $215(30.1)$ & $18(8.4)(5-12.9)$ & \\
\hline $11^{\text {th }}$ & $144(20.2)$ & $20(13.9)(8.7-20.3)$ & \\
\hline $12^{\text {th }}$ & $132(18.5)$ & $23(17.4)(11.38-24.99)$ & \\
\hline Total & 714 & $79(11.0)(8.86-13.6)$ & \\
\hline \multicolumn{4}{|l|}{ Gender } \\
\hline Male & $609(85.3)$ & $62(10.2)(7.89-12.86)$ & $3.287,1,0.07$ \\
\hline Female & $105(14.7)$ & $17(16.2)(9.72-24.65)$ & \\
\hline \multicolumn{4}{|l|}{ Religion } \\
\hline Hindu & $611(85.6)$ & $63(10.3)(8.01-13)$ & $2.546,2,0.280$ \\
\hline Muslim & $81(11.3)$ & $13(16.0)(8.83-25.88)$ & \\
\hline Others & $22(3.1)$ & $3(13.6)(2.91-34.91)$ & \\
\hline \multicolumn{4}{|c|}{ Type of Family } \\
\hline Nuclear & $382(53.7)$ & $39(10.2)(7.36-13.69)$ & $0.610,1,0.435$ \\
\hline Joint & $332(46.3)$ & $40(12.0)(8.75-16.04)$ & \\
\hline \multicolumn{4}{|c|}{ Socioeconomic Status* } \\
\hline High & $234(32.8)$ & $32(13.7)(9.55-18.75)$ & $2.924,2,0.232$ \\
\hline $\begin{array}{l}\text { Upper } \\
\text { Middle }\end{array}$ & $170(23.8)$ & $19(11.2)(6.86-16.90)$ & \\
\hline $\begin{array}{l}\text { Lower } \\
\text { Middle }\end{array}$ & $310(43.4)$ & $28(9.0)(6.09-12.79)$ & \\
\hline
\end{tabular}


Table 2. Exposure to Tobacco at School and SLT Use among Study Subjects $(\mathrm{N}=714)$

\begin{tabular}{|c|c|c|c|c|c|}
\hline \multirow[t]{2}{*}{ Exposure to } & & \multicolumn{2}{|l|}{ SLT use } & \multirow[b]{2}{*}{ Total no $(\%)$} & \multirow[b]{2}{*}{$\chi 2, \mathrm{df}$, 'p' value } \\
\hline & & Present no $(\%)$ & Absent no $(\%)$ & & \\
\hline \multirow[t]{3}{*}{ Tobacco at school premise } & Present & $51(18.4)$ & $226(81.6)$ & $277(100)$ & $24.83 .1,<0.0001$ \\
\hline & Absent & $28(6.4)$ & 409 (93.6) & $437(100)$ & \\
\hline & Total & $79(11)$ & $635(89)$ & $714(100)$ & \\
\hline \multirow[t]{3}{*}{ Teacher using SLT in school } & Present & $17(19.1)$ & $72(80.9)$ & $089(100)$ & $5.77,1,0.016$ \\
\hline & Absent & $62(9.9)$ & $563(90.1)$ & $625(100)$ & \\
\hline & Total & $79(11)$ & $635(89)$ & $714(100)$ & \\
\hline
\end{tabular}

Table 3. Exposure to Tobacco at Social Surroundings and SLT Use among Study Subjects (N=714)

\begin{tabular}{lccccc}
\hline Exposure to Tobacco & \multicolumn{5}{c}{ SLT use } \\
& Frequency (no of days/ week) & Present n (\%) & Absent n (\%) & Total N (\%) & $\chi 2$, df, 'p' value \\
\hline At home & 0 & $23(8.10)$ & $260(91.90)$ & $283(100)$ & $8.37 .3,0.03$ \\
& $1-4$ & $38(11.50)$ & $292(88.50)$ & $330(100)$ \\
At outdoor public place & $5-6$ & $12(20.70)$ & $046(79.30)$ & $058(100)$ \\
& 7 & $06(13.95)$ & $037(86.05)$ & $043(100)$ \\
& Total & $79(11)$ & $635(89)$ & $714(100)$ & $7.88,3,0.04$ \\
& 0 & $10(9.80)$ & $92(90.20)$ & $102(100)$ & $299(100)$ \\
& $1-4$ & $27(9.03)$ & $272(90.97)$ & $164(100)$ \\
\end{tabular}

(19.1\%) of study subjects who were exposed to teacher using SLT in schools compared to non-exposed group. $(\mathrm{p}<0.0001, \mathrm{p}=0.016)$ (Table 2).

It was observed that $23(8.1 \%)$ of study subjects were not exposed to tobacco at home and $10(9.8 \%)$ of study subjects were not exposed to tobacco at outdoor public spaces but still consumed SLT despite having nil exposure. Highest consumption of SLT was amongst 12 (20.7\%) of study subjects who were exposed to tobacco at home for 5-6 days in a week $(\mathrm{p}=0.03)$ and $26(17.4 \%)$ of study subjects who were exposed to tobacco at outdoor place for 7 days in a week compared to other categories of days of exposure per week $(\mathrm{p}=0.04)$ (Table 3$)$.

Consumption of SLT use was significantly higher among 19 (16.7\%) study subjects exposed through social media to tobacco advertisement or promotion than others exposed to television advertisements31 (10.6\%), print media16 $(9.5 \%)$ and exposed through radio $3(3.9 \%)$ $(\mathrm{P}=0.04)$ (Table 4).

\section{Discussion}

In the present study prevalence of SLT use was found to be $11 \%$ which is similar to findings of the cross-sectional study conducted by Kumar et al., (2014) among 962 students of class $11^{\text {th }}-12^{\text {th }}$ in schools of Delhi in 2013, which reported the prevalence of ever tobacco chewers to be $12.5 \%$. The prevalence in the present study was found to be slightly higher than reported by Mukherjee et al., (2012) among 276 students of $8^{\text {th }}-9^{\text {th }}$ class in schools of West Bengal in 2008 that reported $9.8 \%$ of the study participants had ever used SLT (Mukherjee et al., 2012). Study by Narain et al., (2011) among 4,786 students from 17 schools, reported a lower prevalence of $4.6 \%$ among the study subjects who were 'ever tobacco chewer' (Narain et al., 2011). This difference in the prevalence of smokeless tobacco use among these studies can be explained by the different study settings and different periods of time.

SLT consumption among our study subjects increased from $(8.1 \%$ to $17 \%)$ as the grades of their class increased

Table 4. SLT Use in Relation to Exposure to Tobacco Advertisements via Different Mode of Media among Study Subjects

\begin{tabular}{lcccc}
\hline Forms of Media & \multicolumn{3}{c}{ SLT Use } & \\
& Yes no (\%) & No no (\%) & Total no (\%) & $\chi 2$, df, 'p'value \\
\hline TV Advertisement & $31(10.6)$ & $261(89.4)$ & $292(100)$ & $8.320,3,0.04$ \\
Print Media & $16(9.5)$ & $153(90.5)$ & $169(100)$ & \\
Social Media & $19(16.7)$ & $95(83.3)$ & $114(100)$ \\
Radio Broadcast & $3(3.9)$ & $74(96.1)$ & $77(100)$ \\
Total & $69(10.6)$ & $583(89.4)$ & $652(100)$ & \\
\hline
\end{tabular}


from 9 th to $12^{\text {th }}$. This finding was in accordance with the results of a cross-sectional study conducted by Chatterjee et al., (2016) among 10-18 years old school students of Mumbai which reported that the prevalence of smokeless tobacco consumption was $9 \%$ among students from $7^{\text {th }}$ class, $27 \%$ among students from 8 th class and $64 \%$ among students from $9^{\text {th }}$ class (Chatterjee et al., 2016). This highlights the susceptibility of school students in higher class to smokeless tobacco use which could be related to their attitude in consuming smokeless tobacco.

The findings of the present study revealed that higher proportion $(16 \%)$ of females compared to $(10.2 \%)$ of males consumed SLT although not statistically significant, which is in contrast to the findings of the cross-sectional study conducted by Ullah et al., (2018) in Bangladesh among 790 students of secondary schools aged 13- 18 years which reported ever SLT use as $10.2 \%$ in males and $8.3 \%$ in females. The higher proportion of SLT use observed in females could be due to the lesser sample of female participants in the study. Similar difference in the prevalence of ever tobacco use was found in other studies. Kumar et al., (2014) in Delhi reported the prevalence of SLT use to be $20.6 \%$ among males and $11.4 \%$ among females. In another study conducted by Gupta (2018) based on Global Adult Tobacco Survey India (GATS-India) 2009-10 data among 15- 18 years old the prevalence of SLT use was found to be double among males (14\%) as compared to females (7\%) (Gupta, 2018).

The results of the present study revealed that a higher proportion of study subjects $(13.7 \%)$ belonging to high socioeconomic class consumed SLT which is in accordance with the findings of the study conducted by Kumar et al., (2014) among 962 students of class 11th-12th in schools of Delhi which also reported higher prevalence $13.6 \%$ of tobacco use among students of high socio-economic status. The increased use of tobacco with high socioeconomic status may be due to availability of money and higher spending capacity on tobacco among the study subjects .

The findings of the present study were in contrast to the study conducted by Daniel et al., (2008) in Kerala which reported that the prevalence of tobacco use was higher $(24.2 \%)$ among those in the low socioeconomic group than in the middle (13.3\%) and high socioeconomic groups (3.2\%) (Daniel et al., 2008).

The results of this study revealed that exposure to tobacco (smoked/ smokeless) amongst peers, teachers and other school staff at school premise was significantly associated with the consumption of SLT in the study subjects which is in concordance with the results of study conducted by Hussain et al., (2017) among 2140 adolescents of class 6th- 10thand aged 11-16 years in schools of Karachi. The results of the study revealed that $33.6 \%$ of adolescents who used smokeless tobacco (SLT) and /or betel quid (BQ) saw their teacher using SLT and/ or BQ in school.

It was observed that exposure to tobacco at home and outdoor public place was significantly associated with SLT use among study subjects which is in accordance with the findings of the previous conducted by Kowitt et al., (2019) which reported that adolescents who were exposed to secondhand smoke, compared to those who were not exposed, had greater odds of initiating SLT use (AOR: 2.71, 95\% CI: 1.60, 4.59).

In this study, it was observed that there was significantly higher consumption of SLT among study subjects who were exposed through social media to tobacco advertisement/ promotion than other modes of media. It was different as compared to findings in the study conducted by Singh et al., (2015) which reported that television $58 \%$ was the main source of exposure for tobacco products followed by newspapers $26 \%$ and movies $16 \%$. This difference in the results can be explained due to different study timings.

In conclusion, the total prevalence of smokeless tobacco use among study subjects was $11 \%$. Consumption of smokeless tobacco was higher (16\%) among females than males (10.2\%) although not statistically significant. Factors such as exposure to tobacco at home, public places, at school and school teacher using smokeless tobacco (SLT), being exposed to tobacco advertisement and promotion via different mode of media was found to be associated with the use of SLT in the study subjects.

Thus, there is a dire need to intensify the activities for identification of current SLT users among school going adolescents in the community so as to identify the vulnerable groups, counsel them and catch them young for prevention and control of tobacco. School-based health promotion programme should be undertaken intensively to address and alert the vulnerable student population about the harmful effects of tobacco use. Lifestyle skills including refusal of tobacco products through skill-based programs for youth must be developed to empower them with ability to refrain from tobacco use.

\section{Author Contribution Statement}

Conceptualization:AK,CD,PS; Design:AK,SG,CD,PS; Definition of intellectual content: AS,SG,MMS,CD; Literature search: AS,CD; Data acquisition: AS,CD; Data analysis: AS,SG,MMS,CD; Statistical analysis: AS,SG,MMS,CD; Manuscript preparation: AS,CD; Manuscript editing: AS,SG,MMS,CD; Manuscript review: $\mathrm{SG}, \mathrm{MMS}, \mathrm{CD}, \mathrm{PS}, \mathrm{AB}$.

\section{Acknowledgements}

The authors wish to thank to the District In-charge, North West A, School Health Scheme, Directorate General of Health Services (DGHS), Delhi (Permission letter dated 09/05/2019) for giving permission to conduct research in Government schools of Delhi, India.

\section{Funding}

The authors declare that the study has been conducted as the primary author's (AS) part of thesis while perusing post-graduation from Faculty of Medical Sciences, University of Delhi in the specialty of Community Medicine. There is no financial or any other way of support required for this article. 
Ethics

Ethical approval was given by Institutional Ethics Committee, Maulana Azad Medical College and Associated Hospitals, Delhi, India (Ref no F.No.17/IEC/ MAMC/2018 dated 26/10/2018).

\section{Conflict of Interest}

The authors of this paper declare no conflict of interest related to financial support or relationships during the proposal writing, data collection, analysis and manuscript writing.

\section{References}

Chadda RK, Sengupta SN (2002). Tobacco use by Indian adolescents. Tob Induced Dis, $\mathbf{1}, 8$

Chatterjee N, Todankar P, Mandal G, et al (2016). Factors associated with tobacco use in students attending local government schools in Mumbai, India. Asian Pac J Cancer Prev, 17, 5075-80.

Daniel AB, Nagaraj K, Kamath R (2008). Prevalence and determinants of tobacco use in a highly literate rural community in southern India. Natl Med J India, 21, 163-5.

Gupta A (2018). Tobacco use behaviour among minors in India. Tob Induced Dis, $\mathbf{1 6}$

Hussain A, Zaheer S, Shafique K (2017). Individual, social and environmental determinants of smokeless tobacco and betel quid use amongst adolescents of Karachi: a school-based cross-sectional survey. BMC Public Health, 17, 913.

Kowitt SD, Goldstein AO, Sutfin EL, et al (2019). Adolescents' first tobacco products: Associations with current multiple tobacco product use. PLoS One, 14, e 0217244.

Kumar V, Talwar R, Roy N, et al (2014). Psychosocial Determinants of Tobacco Use among School Going Adolescents in Delhi, India. J Addict, 2014, 170941.

Mishra G, Gupta V, Kumar S (2019). Prevalence of tobacco use among school teachers in Lucknow: A Cross Sectional Study. Pravara Med Rev, 11, 19-25.

Mukherjee A, Sinha A, Taraphdar P, et al (2012). Tobacco abuse among school going adolescents in a rural area of West Bengal, India. Indian J Public Health, 56, 286-9.

Nagler EM, Sinha DN, Pednekar MS, et al (2015). Social contextual factors and tobacco use among Indian teachers: insights from the Bihar School Teachers' Study. Prev Med, 74, 24-30

Narain R, Sardana S, Gupta S, et al (2011). Age at initiation \& prevalence of tobacco use among school children in Noida, India: a cross-sectional questionnaire based survey. Indian J Med Res, 133, 300-7.

Oswal KC (2015). Factors associated with tobacco use among adolescents in India: results from the Global Youth Tobacco Survey, India (2000-2003). Asia Pac J Public Health, 27, Np203-11.

Sinha DN, Palipudi KM, Rolle I, et al (2011). Tobacco use among youth and adults in member countries of South-East Asia region: review of findings from surveys under the Global Tobacco Surveillance System. Indian J Public Health, 55, 169-76.

Sinha DN (2021). Gutka advertisement and smokeless tobacco use by adolescents in Sikkim, India. Indian J Commun Med, $\mathbf{3 0}$.

Singh S, Vijayakumar N, Priyadarshini HR, et al (2015). Tobacco use among high school children in Bangalore, India: A study of knowledge, attitude and practice. Indian J Cancer, 52, 690-3.

Soni P, Raut DK (2013) Tobacco use among school students in National Capital Territory of Delhi. J Alcoholism Drug Depend, 1, 120

Preeti Sonni RD (2013). Tobacco use among school students in national capital territory of Delhi. J Alcohol Drug Depend, 1, 1-5.

Thakur D, Gupta A, Thakur A, et al (2014). Prevalence of cigarette smoking and its predictors among school going adolescents of North India. South Asian J Cancer, 3, 193-5.

Ullah MZ, Lim JN, Ha MA, et al (2018). Smokeless tobacco use: pattern of use, knowledge and perceptions among rural Bangladeshi adolescents. PeerJ, 6, e5463.

Vaidya SG, Naik UD, Vaidya JS (1996). Effect of sports sponsorship by tobacco companies on children's experimentation with tobacco. $B M J, \mathbf{3 1 3}, 400$.

Veeranki SP, Mamudu HM, John RM, et al (2015). Prevalence and correlates of tobacco use among school-going adolescents in Madagascar. J Epidemiol Glob Health, 5, $239-47$.

WHO | What about Boys: A Literature Review on the Health and Development of Adolescent Boys [WWW Document] (2000), URL https://apps.who.int/iris/handle/10665/66487 (accessed 8.25.20)

WHO |Adolescent health [WWW Document], n.d. URL https:// www.who.int/health-topics/adolescent-health\#tab=tab_1 (accessed 8.25.20)

WHO $\mid$ Adolescent health in the South-East Asia Region [WWW Document], n.d. URL https://www.who.int/southeastasia/ health-topics/adolescent-health (accessed 8.25.20).

WHO | India (Ages 13-15) Global Youth Tobacco Survey (GYTS). Fact Sheet [WWW Document], n.d. URL https:// www.who.int/fctc/reporting/Annexoneindia.pdf (accessed 8.25.20).

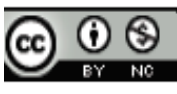

This work is licensed under a Creative Commons AttributionNon Commercial 4.0 International License. 